\title{
Interpreting Semitic Protolanguage as a Conlag or Constructed Language I
}

\author{
Edouard G. Belaga \\ Université de Strasbourg, Strasbourg, France
}

\begin{abstract}
One of the most natural approaches to the problem of origins of natural languages is the study of hidden intelligent “communications” emanating from their historical forms. Semitic languages history is especially meaningful in this sense. One discovers, in particular, that $\mathrm{BH}$ (Biblical Hebrew), the best preserved fossil of the Semitic protolanguage, is primarily a verbal language, with an average verse of the Hebrew Bible containing no less than three verbs and with the biggest part of its vocabulary representing morphological derivations from verbal roots, almost entirely triliteral-the feature BH shares with all Semitic and a few other Afro-Asiatic languages. For classical linguists, more than hundred years ago, it was surprising to discover that verbal system of BH is, as we say today, optimal from the Information Theory's point of view and that its formal topological morphology is semantically meaningful. These and other basic features of BH reflect, in our opinion, the original design of the Semitic protolanguage and suggest the indispensability of IIH-Inspirational Intelligence Hypothesis, our main topic - for the understanding of origins of natural languages. Our project is of vertical nature with respect to the time, in difference with the vastly dominating today horizontal linguistic approaches.
\end{abstract}

Keywords: Semitic languages, protolanguage, verbal system, origins of natural languages, artificial intelligence, conlagor constructed language, VBBH (Verbal Body of Biblical Hebrew), IIH (Inspirational Intelligence Hypothesis)

Language is one of the hallmarks of the human species - an important part of what makes us human. Yet, despite a staggering growth in our scientific knowledge about the origin of life, the universe and (almost) everything else that we have seen fit to ponder, we know comparatively little about how our unique ability for language originated and evolved into the complex linguistic systems we use today. Why might this be?

Morten H. Christiansen \& Simon Kirby, 2003, p. 300

\section{Introduction: BH (Biblical Hebrew) Perceived by Classical Linguists}

\section{Triconsonantal Morphological Pervasiveness of BH}

$\mathrm{BH}$, the best preserved fossil of the Semitic protolanguage (Huehnergard, 2011), could be seen as primarily a verbal language (Bergen, 1994), with an average verse of the Hebrew Bible containing no less than three verbs and with the biggest part of its vocabulary representing morphological derivations from verbal roots (Joosten, 2012), almost entirely triliteral, or triconsonantal (Gesenius, 1813, 1952) — the feature BH shares with all Semitic and a few other Afro-Asiatic languages (Ehret, 1995).

The unique peculiarity of this triconsonantal morphological pervasiveness did not completely escape the

Edouard G. Belaga, doctor, Institut de Recherche Mathématique Avancée, Université de Strasbourg. 
attention of previous generations of Western linguists, as shows the following "methodological" warning opening a popular Hebrew grammar edited more than a century ago:

Hebrew, of course, has difficulties of its own, which must be frankly faced. ... [In particular,] the roots are almost entirely triliteral, with the result that, at first, the verbs at any rate all look painfully alike-e.g., malak, zakar, lamad, harag, etc.- thus imposing upon the memory a seemingly intolerable strain. Compound verbs are impossible: there is nothing in Hebrew to correspond to the great and agreeable variety presented by Latin, Greek, or German in such verbs as exire, inire, abire, redire, ... ausgehen, eingehen, aufgehen, untergehen, etc. Every verb has to be learned separately; the verbs to go out, to go up, to go down are all dissyllables of the type illustrated above, having nothing in common with one another and being quite unrelated to the verb to go. (Davidson, 1916, pp. 1-2)

\section{Three Extraordinary Fundamental Linguistic Phenomena}

This amusing résumé has the merit to recognize, even if under the guise of an earnestly banal pedagogical clueing in, three extraordinary fundamental linguistic phenomena common to all Semitic languages:

First, the extreme parsimoniousness, one could say optimality, from the point of view of Information Theory, of the triconsonantal representation of verbs: With more than one and less than 2,000 known BH verbs, two consonants would be not enough and four would be too much: The BH dictionary has about 1,700 verbs among about 8,000 words.

Second, the meaningful morphological topology of the body of BH verbs, a fundamental feature of the BH architecture. Two triconsonantal verbs are morphologically or, equivalently, topologically neighboring if they differ in just one consonant, with many pairs of topological neighbors having close, or similar, or related semantical values (Clark, 1999).

Third, even more surprising and subtle: This feature of $\mathrm{BH}$ of mixed morphologic-semantic nature manifests not only the pervasiveness of the phenomenon of topologically neighboring verbs having semantically meaningful correlations-such correlations are often relating to the type of the particular letters involved (Clark, 1999).

Thus, the verb to go, "he-lamed-kaph", meaning to progress step by step toward a goal, is both semantically and morphologically neighboring the verb "he-lamed-qoph", meaning divide and portion, and not the verbs to go out, to go up, and to go down, which are neighboring the verbs to extend, to master, and to scrape or scratch, respectively.

\section{The Ancient Hebrew Vocabulary Must Have Been Markedly Larger}

These exquisite-combinatorial, topological, and communicative-precision, efficiency, and evocativeness are the real source of the so much deplored above difficulty of mechanical memorization of $\mathrm{BH}$ verbs, the difficulty which, according to (Ullendorff, 1971), would be considerably aggravated if the quoted manual should be written somewhen in between the third and second millennium BC: "It has, of course, long been recognized that the ancient Hebrew vocabulary must have been markedly larger than that preserved in the OT [Old Testament, alias Hebrew Bible]” (Ullendorff, 1971, p. 242).

\section{Communicative Awareness and Inspirational Intelligence}

\section{Inspirational Intelligence Hypothesis}

Summarizing the above observations, we arrive at the following central problem of our project:

Main problem. What is the meaning and what are the origins of these unique and fundamental attributes of $\mathrm{BH}$, primarily verbal language, with most of words of its dictionary derived from verbal roots? We speak 
here of the highly innate, morphologically most parsimonious, semantically efficiently involved formal structure of its verbal system, displaying also a unique language-alphabet relationship, closely resembling in particular, and yet vastly superior in its expressive power to humanly designed assembler languages.

Our conclusion, stipulated and developed below, cannot be formulated otherwise than:

IIH (Inspirational Intelligence Hypothesis). The assumption that the hypothetical protolanguage preceding BH and other known Semitic languages, and called here Semitic protolanguage, has appeared or emerged, spontaneously and during a relatively short period of time, in and from a single person or a single family. In other words, its emergence is of inspirational nature, sort of a very personal "poem", reflecting the innermost vital, moral, spiritual, and intellectual "architecture” and aspirations of certain human beings.

The real presence of inspirational creativity—related to physics or biological, linguistic, cultural, and social contexts-is somehow eluding today the scientific curiosity. To confirm the reality and the validity of our intuition in the linguistic and cultural context, it will suffice to mention the example of the Russian poetic genius Alexander Puchkin (1799-1837) who almost singlehandedly initiated the modern culture of Russian language and literature, better — the Russian modern culture tout court (Bethea \& Dolinin, 2005) (see Figure 1).

\begin{tabular}{|c|c|c|c|c|c|c|c|c|c|c|c|c|c|c|c|c|c|c|c|c|c|}
\hline 22 & 21 & 20 & 19 & 18 & 17 & 16 & 15 & \begin{tabular}{|l|}
14 \\
\end{tabular} & 13 & 12 & 11 & 10 & 09 & 08 & 07 & 06 & 05 & 04 & 03 & \begin{tabular}{|l|}
02 \\
\end{tabular} & 01 \\
\hline ת & ש & 7 & $P$ & $\mathbf{Y}$ & פ & $y$ & $D$ & J & $n$ & ל & כ & 1 & $v$ & $\Pi$ & T & 1 & 7 & $\mathrm{~T}$ & $\lambda$ & ב & $N$ \\
\hline & & & & $Y$ & 7 & & & 1 & 口 & & 7 & & & & & & & & & & \\
\hline $\begin{array}{l}\mathrm{t} \\
\mathrm{a} \\
\mathrm{v}\end{array}$ & $\begin{array}{l}\mathrm{s} \\
\mathrm{h} \\
\mathrm{i} \\
\mathrm{n}\end{array}$ & $\begin{array}{l}\text { r } \\
\text { e } \\
\text { s } \\
\text { h }\end{array}$ & $\begin{array}{l}q \\
o \\
p \\
h\end{array}$ & $\begin{array}{l}\mathrm{t} \\
\mathrm{z} \\
\mathrm{a} \\
\mathrm{d} \\
\mathrm{e}\end{array}$ & $\begin{array}{l}\mathrm{p} \\
\mathrm{e}\end{array}$ & $\begin{array}{l}\mathrm{a} \\
\mathrm{i} \\
\mathrm{n}\end{array}$ & $\begin{array}{c}\mathrm{s} \\
\mathrm{a} \\
\mathrm{m} \\
\mathrm{k} \\
\mathrm{h}\end{array}$ & $\begin{array}{l}\mathrm{n} \\
\mathrm{u} \\
\mathrm{n}\end{array}$ & $\begin{array}{c}\mathrm{m} \\
\mathrm{e} \\
\mathrm{m}\end{array}$ & $\begin{array}{l}1 \\
\mathrm{a} \\
\mathrm{m} \\
\mathrm{e} \\
\mathrm{d}\end{array}$ & $\begin{array}{l}\mathrm{k} \\
\mathrm{a} \\
\mathrm{p} \\
\mathrm{h}\end{array}$ & $\begin{array}{l}\mathrm{y} \\
0 \\
\mathrm{~d}\end{array}$ & $\begin{array}{l}\mathrm{t} \\
\mathrm{e} \\
\mathrm{t} \\
\mathrm{h}\end{array}$ & $\begin{array}{l}\mathrm{h} \\
\mathrm{e} \\
\mathrm{t} \\
\mathrm{h}\end{array}$ & $\begin{array}{l}\mathrm{z} \\
\mathrm{a} \\
\mathrm{i} \\
\mathrm{n}\end{array}$ & $\begin{array}{l}\mathrm{w} \\
\mathrm{a} \\
\mathrm{w}\end{array}$ & $\begin{array}{l}\mathrm{h} \\
\mathrm{e}\end{array}$ & $\begin{array}{l}\mathrm{d} \\
\mathrm{a} \\
1 \\
\mathrm{e} \\
\mathrm{t} \\
\mathrm{h}\end{array}$ & $\begin{array}{c}\mathrm{g} \\
\mathrm{h} \\
\mathrm{i} \\
\mathrm{m} \\
\mathrm{m} \\
\mathrm{e} \\
1\end{array}$ & \begin{tabular}{|c|}
$\mathrm{b}$ \\
$\mathrm{e}$ \\
$\mathrm{t}$ \\
$\mathrm{h}$
\end{tabular} & $\begin{array}{l}\mathrm{a} \\
1 \\
\mathrm{e} \\
\mathrm{p} \\
\mathrm{h}\end{array}$ \\
\hline
\end{tabular}

Figure 1. The Hebrew alphabet.

\section{Communicative Awareness}

The computational modeling is today the most powerful technical universe for playing in, around, and out different scenarios of emergence and evolution of natural languages (Jurafsky \& Martin, 2000). Pre-adaptation for emergence, biological and cultural apparatuses for evolution and natural selection, genetic and archaeological evidence, etc. (Pinker \& Bloom, 1990): Those are global scientific concepts and ideological schemes dominating our linguistic field—unfortunately without much success (Christiansen \& Kirby, 2003).

Our approach will be different. To simplify, if not caricature the matter, one can compare it to methods of SETI (Search for Extraterrestrial Intelligence) (Swift, 1993), without attributing to this modern field the importance its protagonists aspire.

More precisely, we will restrict our attention to hidden intelligent "communications" emanating from evolving historical forms of Semitic protolanguage, as those forms are reflected in the structure of its best preserved fossil, BH. Then we will try to understand the meaning of these communications and its implications for the problem of emergence of our Semitic protolanguage.

\section{Historical Role of the Semitic Protolanguage}

For those of our readers who might be doubting the value of constructing a research project on emergence of natural languages around such a "rare poisson" as $\mathrm{BH}$, let us remark that we are sharing the assumption, 
many times and in many ways demonstrated linguisticly, that its Semitic protolanguage was the principal source for all modern European and many Asia-African languages (Huehnergard, 2011).

\section{Verbal Structure of BH and of Its Protolanguage}

\section{Verbal Triliterality}

The Hebrew verb is known for its remarkable linguistic "enigmas" (McFall, 1982). Ours start with a trivial observation that, with the exception of several dozen double two-letter cases, all Hebrew verbs are triliteral, or triconsonantal—-three-letter combinations over the Hebrew alphabet of 22 letters (see Figure 1). In other words, about 1,700 of these verbs can be presented by points of the discrete cube BH Verbs, BHV $=22 \times 22 \times 22=10,648$.

There is no doubt that, taking by itself, its notoriety notwithstanding, this unique linguistic phenomenon should arise today one's scientific curiosity — be it just because of the striking similitude of the abstract perfection and parsimoniousness of such an alphabetical coding of verbs to the way machine codes (low level, or assembly programming languages) (Pratt \& Zelkowitz, 2001) are traditionally represented—by mostly three Latin letters combinations (abbreviations), with a very few codes having two- and four-, or more-letter names.

Add to this surprising formal similarity, first, the well-known but still lacking any evolutionary explanation fact that "Hebrew grammar is essentially schematic and, starting from simple primary rules, it is possible to work out, almost mathematically, the main groups of word-building” (Lambek \& Yanofsky, 2006; Weingreen, 1959); and the second, even more surprising, subtle, of a mixed morphologic-semantic nature feature of $\mathrm{BH}$ - the pervasiveness of the phenomenon of topologically neighboring (for example, differing in only one letter position) verbs having semantically meaningful correlations, often related to the type of the particular letters involved (Clark, 1999).

The very existence of such a semantically meaningful relationship represents a novel, and for that matter, giant conceptual leap from the pure phonetical role an alphabet-interpreted by modern evolutionary theories as a phonetically oriented dead end of a gradual random simplification of the hieroglyphical systems (Healey, 1990) - supposed to play, and the change of the linguistic perspective at least as radical as the passage from a hieroglyphical coding of words-notions to their phonetically meaningful alphabetic protocols.

\section{Organismic Linguistics}

Let us think now back to the mentioned above classical appreciation of the difficulties of BH: "[Its] roots are almost entirely triliteral, with the result that, at first, the verbs at any rate all look painfully alike—e.g., malak, zakar, lamad, harag, etc.—thus imposing upon the memory a seemingly intolerable strain” (Davidson, 1916, p. vi).

Thus, because "language is one of the hallmarks of the human species-an important part of what makes us human” (Christiansen \& Kirby, 2003) (our epigraph), one can conclude that profound intimate linguistic preferences of English speaking people yesterday and today are different from those of people who spoke the other day $\mathrm{BH}$ and, before, its protolanguage.

In other words, to this second category of women and men, the BH verbs were not at all looking alike!

In particular, we observe that some points of the "verbal body" of BH were connected between them by the sensitive passages — change of only one consonant— to their neighbors:

Thesis: Organismic BH Linguistics. The compact trilateral "verbal body" of BH is an extremely sensitive organismic fundament of human proto-Semitic linguistic ability. 


\section{Triliterality as an Essential Feature of Semitic Protolanguage}

Were these properties specifically BH or were they "projected" on BH from more ancient proto-Semitic languages?

The modern redaction of the cited above classical BH grammar (Davidson, 1916) creates an impression that this verbal BH compactness was acquired later: "The roots, whatever may have been their original form, are in the Old Testament almost entirely triliteral” (Mauchline, 1978, p. 6).

However, all studies of Semitic languages, living and dead, demonstrate convincingly that verbal triliterality was an essential feature of Semitic protolanguage. And this feature does not imply either particular difficulty—compared to modern English—-to learn and to use this protolanguage, or poverty of its expressive power.

Quite to the contrary—whereas in the above English example (see "Triconsonantal Morphological Pervasiveness of Biblical Hebrew" of section "Introduction: BH (Biblical Hebrew) Perceived by Classical Linguists") the verbs to go, to go out, to go up, to go down achieve semantical variations by outward combinatorial means applied to the unanalyzable basic word go, BH verbs are referring by their triliteral structure — which is related by vicinages to similar verbs and which implies the immanence of an alphabet—-to some innermost realities of the human being:

Thesis: Verbal Body of Semitic Protolanguage. (1) Verbal body of Semitic protolanguage was an organismic (Goldstein, 1939/1995) linguistic system with explicit and deep links to biological, psychological, intellectual, spiritual, and social aspects of human life; (2) Morphologically, this verbal body was absolutely dominant, implying an extremely dynamic appeal to women and men exercising this protolanguage; (3) We cannot characterize in the same way the verbal body of modern Hebrew, even if its creators were very sensible to the ancient origins of that language; (4) As to the verbal systems of modern natural languages, they should be characterized as verbal collections, without any substantial universal and unifying links between verbs; (5) Verbal body similar to that of $\mathrm{BH}$ cannot be expected to appear in a process of acquiring accidental improvements. Its existence is the result of a linguistic construction-Semitic protolanguage was a constructed language-Conlag (Okrent, 2009); and (6) One can expect to partially reconstruct this system by understanding the semantical meaning and the alphabetic references of verbal neighborhoods in the BH verbal body.

\section{Getting out of the Natural Selection Stampede to Clean up Our Epistemic Act}

\section{Charles Darwin vs. Johannes Kepler}

The challenge of our BH problem has been from the very beginning complicated by a universal, unspoken, and yet not less bounding methodological assumption that any evolutionary solution should be consistent with, if not inspired by, the natural selection paradigm (Gould, 2002).

More generally, Charles Darwin fundamental idea-before and independently of his elaborated doctrine- that the biological reality is permanently in a natural movement, in a flow of renewal, accompanied by accidental mutations, with some of them leading to radical improvement of species - this popularity has finally eliminated from the scientific horizons all "theological” interest à la Johannes Kepler (Wolfenstein, 2003) in Why?, Thanks to what?, For what purpose?, and Who? (Kepler, 1619). Thus, for example, the only ambition of Optimality Theory (Prince \& Smolensky, 1993/2002/2004) was, and remains, to introduce and to investigate some natural constrains on the linguistic flow of languages- the flow supposed to bring our languages from speechless vocality or manual nothing to their modern splendor. 
We believe that the truth, at least in our case, turned out to be different, and the vision elaborated in this study has been won out by the author-looking since about 20 years for a meaningful interpretation of the mysterious linguistic phenomena outlined above-over the considerable psychological pressure, and at the prize of a painstaking sorting out the enormous body of relevant emergence-and-evolution-by-natural-selection publications, with their characteristic authoritative-because emanating from this theory of everything (Laughlin \& Pines, 2000)—and yet, to our great disappointment, absolutely unconvincing, even if often computer-oriented and -supported, claimed Gray and Atkinson (2003).

\section{Does Design Come After Evolution?}

A typical sample—a veritable statement of metaphysical faith, publicly and solemnly delivered by Robert Dawkins (2005) and having the merit to be short, clear, and uncompromising—could help an outsider to have a taste of, without acquiring it for, the prevailing atmosphere:

I believe, but I cannot prove, that all life, all intelligence, all creativity and all "design” anywhere in the universe, is the direct or indirect product of Darwinian natural selection. It follows that design comes late in the universe, after a period of Darwinian evolution. Design cannot precede evolution and therefore cannot underlie the universe. (p. 5)

And many, many, too many have tried to be faithful to this condemnation of the design creativity to work out accidentally as it were: (1) biology (Dawkins, 1986), cosmology (Smolin, 2004), behavioral psychology (Crawford \& Krebs, 1998), and lingustics (Pinker \& Bloom, 1990); (2) all progress of sciences at large (Weinberg, 2001) and even more radically; (3) all intellectual endeavors and failures (Dennett, 2006) of humanity, if not; and (4) the very existence in, and ultimately, of the Universe (Dawkins, 2005).

\section{The Prototype of Laplacian Mechanics}

To begin with, let us remind the reader that, historically, there is nothing new or extraordinary when a venerable (in our case, spelled out by a 19th century economist (Malthus, 1803)) scientific concept outlives its epistemological usefulness and becomes an epistemological burden for science. Two following well-known precedents should illustrate the point:

Laplacian Mechanics created more than two hundred years ago and universally admired ever since - that is, until the advent of Maxwell's, Poincaré's, and Einstein's theories—has ultimately lost its epistemological value for physics, to acquire instead an enormous ideological prestige as an authentic and unsurpassed in its perfection instance of reductionist philosophy which, in particular, underlay the corresponding dogmatic distortions of otherwise valuable scientific discoveries of, say, Charles Darwin, Karl Marx, and Sigmund Freud.

This is how Einstein (1998) has summarized the post-Laplacian epistemological crisis in physics:

We must not be surprised, therefore, that, so to speak, all physicists of the last [19-th] century saw in classical mechanics a firm and final foundation for all physics, yes, indeed, for all natural science, and that they never grew tired in their attempts to base Maxwell's theory of electromagnetism, which, in the meantime, was slowly beginning to win out, upon mechanics as well. (p. 73)

Little has Einstein known, delivering this post-mortem of a formerly omniscient theory, that he himself has fallen under the spell of the commonly accepted—at least, since Isaak Newton—Classical Causality Doctrine of Space and Time, the very conceptual ground on which Pierre-Simon Laplace has proudly erected his miniature mechanical universe. 
To his credit, Einstein was able to spell out himself his difficulty to understand some quantum micro-phenomena incompatible with the classical causality doctrine, by inventing his now famous Gedanken experiment exhibiting, as he called it, a "spooky action on a distance".

We speak here about the well-known, systematically exploited, and yet as poorly understood today as in Einstein's times phenomenon of quantum entanglement that, after being discovered according to the very scenario advanced by Einstein and his colleagues as improbable (Einstein, Podolsky, \& Rosen, 1935), dominates the modern research in Quantum Information Processing (Nielsen \& Chuang, 2000).

\section{Computer Metaphor as the First, Best Hope of Materialism}

The subtlety of this pure physical phenomenon, of its philosophical and theoretical repercussions and accommodations, and of related theoretical experimental discoveries which might one day lead to the creation of presently still even theoretically unconceivable Quantum Computer, most strikingly contrasts with the 19th century scientism still limiting and burdening the imagination of many cognitive scientists—as illustrated by the following recent credo (Hobbs, 2007), found in the mentioned above and otherwise very instructive compendium (Arbib, 2007) on the mirror system hypothesis on the linkage of action and language:

[T] he central metaphor of cognitive science, “The brain is a computer”, gives us hope. Prior to the computer metaphor, we had no idea of what could possibly be the bridge between beliefs and ion transport. Now we have an idea. In the long history of inquiry into the nature of mind, the computer metaphor gives us, for the first time, the promise of linking the entities and processes of intentional psychology to the underlying biological processes of neurones, and hence to physical processes. We could say that the computer metaphor is the first, best hope of materialism. (Hobbs, 2007, p. 50)

What physical processes have had the author in mind formulating this statement of scientific belief: only classical, or quantum, the "spooky" ones including, or some other, now either on the stage of preliminary studies, or as yet not discovered, eventually even more paradoxical ones? What sort of Materialism informs his scientific vision—Laplacian, or Einsteinian, or more modern, said Zeilingerian (Zeilinger, 2005) (which would not be recognized as "Materialism" neither by Laplace nor by Marx, and probably not even by Dennett), or its futurist version, not yet invented? And on what idea of Computer relies his metaphor-the abacus, Charles Babbage's programmable mechanical computer, the modern transistor-based, integrated circuit computer, the futurist quantum computer project, or a future computing device based on new revolutionary philosophical, physical, chemical, or other scientific principles, today not even dreamt about?

\section{Natural Languages Without Natural Selection}

In fact, transposed to such fields as the studies of the emergence and evolution of natural languages, of science (Belaga, 2008), etc., from the strictly biological scene-with its immense variety of species, genera, etc., with its times of engagement ranging from at most hundred years of life expectancy for an individual organism to at least millions and even billions of years for evolutionary processes to bring this or that organism to existence, and with the fundamental scarcity of the material traces (fossils) of both biological organisms and their evolutionary changes-natural selection conjecture becomes for the first time verifiable and, if it should be eventually the case, falsifiable (Popper, 1963).

This eventuality, neither deals there with, nor bears directly on our proceedings or conclusions, has everything to do with the three following well-known linguistic (and more general, cognitive) (Belaga, 2008) facts of fundamental epistemological importance-with particular instances of the second and the third ones 
providing us, as it was already mentioned above (see "Three Extraordinary Fundamental Linguistic Phenomena” of section "Introduction: BH (Biblical Hebrew) Perceived by Classical Linguists”), with both the object and instruments of our enquiry:

First, the number of natural languages, living or dead, does not exceed several hundreds, with the life span of a typical natural language, our linguistic "organism”, varying from several hundred to several thousand years, compared to at most several million years of modern languages existence; respectively, the number of principal natural languages families (the linguistic genera) does not exceed several dozens.

Second, the linguistic "fossils" are relatively numerous, very well preserved, and mostly very good documented and studied - to faithfully testify both to the state of particular languages at particular historical junctures and to their evolutionary changes.

Third and last, but not least, linguistics is the theory of language used in materially preserved exchanges, sometimes very intelligent and detailed, between individuals and personal announcements, sometimes very deep and substantial. These exchanges and announcements bear in many cases some important information about the emergence of the language:

Thesis: Higher Memory Level of Linguistic Fossils. Alongside the traditionally studied first, or low, or material memory level of linguistic fossils extracted from preserved (and mostly archeologically retrieved) inscriptions and texts - the level corresponding to the one and only one known in the case of biological fossils - fossilized languages often possess a higher memory level: the stories told by preserved texts about the (history of the) very language in which they were written.

As in the case of the first level memory possessing by preserved inscriptions and texts, but on a different methodological basis, the stories which preserved the higher memory level need a careful and critical examination before being admitted as trusted testimonies to the history of the language in question. But if ultimately admitted, the extracted information, otherwise unavailable, might be of an extraordinary importance: Just imagine that, alongside our studies of fossils of an extinct dinosaur, we could also hear from him his generation’s story!

\section{Conclusions}

Our approach reverses the only direction of research known today toward the origins and structural meaning of natural languages. We believe that, similar to physical phenomena, we should learn a lot from their original and fully independent of simplistic evolutionary paradigms structures.

\section{References}

Arbib, M. A. (Ed.). (2007). Action to language via the Mirror Neuron System. Cambridge: Cambridge University Press.

Belaga, E. (2008). In the beginning was the verb: The emergence and evolution of language problem in the light of the big bang epistemological paradigm. Rivistadi Filologia Cognitiva (Cognitive Philology), 1(1), 1-17.

Bergen, R. D. (Ed.). (1994). Biblical Hebrew and discourse linguistics. Winona Lake, USA: Eisenbrauns.

Bethea, D. M., \& Dolinin, A. (2005). The Pushkin handbook. Madison: University of Wisconsin Press.

Christiansen, M. H., \& Kirby, S. (2003). Language evolution: Consensus and controversies. TRENDS in Cognitive Sciences, 7(7), $1-15$.

Clark, M. (1999). Etymological dictionary of Biblical Hebrew: Based on the commentaries of Samson Raphael Hirsch. Jerusalem: Feldheim Publishers.

Crawford, C. B., \& Krebs, D. L. (Eds.). (1998). Handbook of evolutionary psychology: Ideas, issues, and applications. Mahwah, N.J.: Lawrence Erlbaum Ass.. 
Davidson, A. B. (1916). An introductory Hebrew grammar with progressive exercises in reading, writing and pointing. Edinburgh: Clark.

Dawkins, R. (1986). The blind watchmaker: Why the evidence of evolution reveals a universe without design. Bethesda, M.D.: Adler \& Adler.

Dawkins, R. (2005, January 3). What do you believe is true even though you cannot prove it?. New York Times, p. 5.

Dennett, D. (2006). Breaking the spell: Religion as a natural phenomenon. London: Penguin.

Ehret, C. (1995). Reconstructing proto-Afroasiatic (proto-Afrasian): Vowels, tone, consonants, and vocabulary. Berkeley: University of California Press.

Einstein, A. (1998). Autobiographical notes. In P. A. Schilpp (Ed.), Albert Einstein: Philosopher-scientist (pp. 1-95). London: Cambridge University Press.

Einstein, A., Podolsky, B., \& Rosen, N. (1935). Can quantum mechanical description of physical reality be considered complete? Phys. Rev., 47, 777.

Gesenius, H. F. W. (1813). Hebraische grammatik. (E. Kautzsch Trans.). Oxford: Clarendon Press.

Gesenius, H. F. W. (1952). A Hebrew and English lexicon of the old testament. USA: Oxford University Press.

Goldstein, K. (1939/1995). The organism: A holistic approach to biology derived from pathological data in man. New York: Zone Books.

Gould, S. J. (2002). The structure of evolutionary theory. Cambridge (Massachusetts) and London: The Belknap Press of Harvard University Press.

Gray, R. D., \& Atkinson, Q. D. (2003). Language-tree divergence times support the Anatolian theory of Indo-European origin. Nature, 426, 435-439.

Healey, J. F. (1990). The early alphabet (reading the past). Berkeley: University of California Press.

Hobbs, J. R. (2007). The origin and evolution of language: A plausible, strong-AI account. In M. A. Arbib (Ed.), Action to language via the Mirror Neuron System (pp. 48-88). Cambridge: Cambridge University Press.

Huehnergard, J. (2011). Proto-Semitic language and culture. The American heritage dictionary of the English language (5th ed., pp. 2066-2078). Boston and New York: Houghton Mifflin Company.

Joosten, J. (2012). The verbal system of Biblical Hebrew: A new synthesis elaborated on the basis of classical prose. Ein Kerem, Jerusalem: Simor Ltd..

Jurafsky, D., \& Martin, J. H. (2000). Speech and language processing: An introduction to natural language processing, computational linguistics, and speech recognition. Upper Saddle River, N.J.: Prentice Hall.

Kepler, J. (1619). Harmonices Mundi. In J. Field (Trans.), The harmony of the world. Philadelphia: The American Philosophical Society.

Lambek, J., \& Yanofsky, N. S. (2006). A computational approach to Biblical Hebrew conjugation. Retrieved from http://www.sci.brooklyn.cuny.edu/nnoson/hebrew1.pdf

Laughlin, R. B., \& Pines, D. (2000). Theory of everything. Proceedings of the National Academy of Sciences of the United States of America, 97(1), 28-31.

Malthus, T. R. (1803). An essay on the principle of population, or, a view of its past and present effects on human happiness, with an inquiry into our prospects respecting its future removal or mitigation of the evils which it occasions (2nd ed.). London: Johnson.

Mauchline, J. (1978). Davidson's introductory Hebrew grammar (26th ed.). Edinburgh: T. \& T. Clark.

McFall, L. (1982). The enigma of the Hebrew verbal system: Solutions from Ewald to the present day. Cambridge: The Almond Press.

Nielsen, M. A., \& Chuang, I. L. (2000). Quantum computation and quantum information. Cambridge: Cambridge University Press.

Okrent, A. (2009). In the land of invented languages: Esperanto rock stars, Klingon poets, Loglan lovers, and the mad dreamers who tried to build a perfect language. New York: Spiegel \& Grau.

Paty, M. (1993). Einstein philosophe: La physique commepratiquephilosophique (Einstein philosopher: Physics as a practical philosophy). Paris: Presses Universitaires de France.

Pinker, S., \& Bloom, P. (1990). Natural language and natural selection. Behavioural and Brain Sciences, 13(4), 707-784.

Popper, K. R. (1963). Conjectures and refutations: The growth of scientific knowledge. London: Hutchinson.

Pratt, T. W., \& Zelkowitz, M. V. (2001). Programming languages: Design and implementation (4th ed.). Upper Saddle River, New Jersey: Prentice Hall. 
Prince, A., \& Smolensky, P. (1993/2002/2004). Optimality theory: Constraint interaction in generative grammar. Oxford: Blackwell Publishers.

Smolin, L. (2004). Cosmological natural selection as the explanation for the complexity of the universe. Physica A: Statistical Mechanics and Its Applications, 340(4), 705-713.

Swift, D. W. (1993). Seti pioneers-Scientists talk about their search for extraterrestrial intelligence. Tucson: University of Arizona Press.

Ullendorff, E. (1971). Is Biblical Hebrew a language?. Bulletin of the School of Oriental and African Studies, University of London, 34(2), 241-255.

Weinberg, S. (2001). Facing up: Science and its cultural adversaries. Cambridge: Harvard University Press.

Weingreen, J. (1959). A practical grammar for classical Hebrew (2nd ed.). Oxford: Oxford University Press.

Wolfenstein, L. (2003). Lessons from Kepler and the theory of everything. Proceedings of the National Academy of Sciences of the United States of America, 100(9), 5001-5003.

Zeilinger, A. (2005). The message of the quantum. Nature, 438, 743. 